\title{
DE TOEKOMST VAN VERSCHILLENDE CULTURES IN SURINAME.
}

\author{
DOOR
}

\section{TJ. PYTTERSEN.}

\section{Cassave.}

Cassave, Yuca of Maniok is in Suriname zoowel als in geheel tropisch Zuid-Amerika steeds het hoofdvoedsel geweest van de Indiaansche bevolking.

In het hollandsch vinden we er de eerste berichten over in een uit het engelsch vertaald werkje: „Een onpartydige Beschryvinge van Surinam. Gelegen op het vaste Landt van Guiana in Africa. Mitsgaders een Verhael van alle vreemde Beesten, Vogels, Visschen, Slangen ende Wormen: Gelyck mede van de Gewoonheden ende Manieren van dese Colonie. By een gebracht van een Engels Edelman George Warren. Ende overgezet uyt het Engels Tot Amsterdam. By Pieter Arentsz. Boeckverkoper In de Beursstraat in de drie Kapen. $A^{\circ} 1669 . "$

Schrijver begint met iets te vertellen over het oude Teorarica - ook wel Thorarica of Santo Bridges, later door de Zeeuwen Zandpunt, daarna Crommenie genaamd: bestaende in omtrent hondert woninghuysen en een Capelle. Voor deze Stadt is een heel fraye Baye ofte Haven / groot en wyt genoech voor hondert Scheepen.

De Plantagien leggen wel dartigh mylen opwaerts langs de Riviere.

Cassander [Cassave. P.], de welche eygentlyck kan Broot genoemt worden / is van gelycken een Wortel / Soo dick als een Mansbeen; maer van verscheyde gedaente; daer spruyt een boom uyt / van de hooghte van acht voeten: de wortel wort getrocken wanneer de boom een jaer oudt is / en wort herplant met de stocken van den boom / die men in de aerde lecht. 
Indiaansch koorn [Mais. P.] en Zuycker-riet worden geplant in de leegten; Yames en ander voetsel [w. o. cassave. P.] op hooger lant.

Die „leegten" stonden in den regentijd bloot aan „friesses" - overstroomingen - waartegen cassave niet bestand is.

In „Suriname's herleving op nieuwe basis," heb ik reeds uitvoerig de aandacht gevestigd op de streken in de kolonie, welke in aanmerking komen voor een cassavecultuur, zoodat ik hier niet in herhalingen zal vervallen.

Steeds is in de literatuur gewezen op het enorme productievermogen van cassave in Suriname.

Herlein (1718) zegt omtrent cassave:

Haar gewoonlyk Brood is een zekere platte Koeke tamelijk lekker, die zy Cassave noemen, gemaakt van de Manioc-wortel. Het word op deze wyze gemaakt; de wortel, hoe wel zy zomtyds is van de dikte der dye, word gemakkelyk uit d'aarde gerukt.... Maniok-wortel, deze gebruiken d'Indianen in plaatze van Koren, van dewelke men een Brood maakt dat tamelyk lekker is, en dat men Cassave noemt, waarvan we tevoren iets gesproken hebben.

Deze wortel is zo vrugtbaar dat een bunder Lands, daar mee beplant zynde, het meer Perzonen zal voeden als 'er geen zes zouden kunnen doen met de beste Tarwe bezaaid.... Ten einde van 9 maanden is de wortel tot hare rypheid.

Zo d'aarde niet te vogtig is, kan 'er de Wortel haar drie Jaren in behoeden zonder te bederven: alzo dat 'er geen Korensolder nodig is om 'er haar op te leggen, want men trekt haar uit 'er aarde na de mate dat men haar heeft van doen.

Met het oog op een toekomstige cultuur en te nemen proeven komt mij hetgeen $H$. verder zegt interessant voor:

Om deze wortel te doen opkomen, moet men dit hout nemen, en by stokken snyden die omtrent een voet lang zyn. Daar na in den Tuin kuilen maken met een Spâ, en zetten drie van deze stokken op een driehoek in d'aarde die men uit deze kuilen gegraven heeft, en voor welke men een kleine verheven hoop heeft gemaakt: Men noemt dit in de kuile planten.

Maar daar is een andere wyze om de Maniok te planten, dat men noemt te poten met den In-steker, die vaardiger en gemak- 
kelyker is, dog die zulk een schonen nog zo wel geagten Manioc niet voort-brengt.

Dit bestaat niet als in een gat in d'aarde te maken met een Insteker, en daar het hout van den Manioc regt over einde in te poten. Maar men moet agt nemen die plant ende, de kwasten niet na-beneden te stellen, om dat als dan de stokken niet zoude voortschieten....

Daar zyn verscheidene zoorten van deze Boomtjes, die niet onderscheiden zyn als in de verwe van de schorze van haar hout, en van hare Wortel.

Welker schorze grys, of wit, of groen is maken een Brood van goeden smaak, en zy groeien in weinig tyd: Maar de wortelen die zy voortbrengen zyn van zo goeden bewaring niet, en zy vermenigvuldigen zo niet als die van den roden of violetten Manioc, die de gemeenste is, de meest-geagte, en d' allervoordeligste in de huishouding....

Hartsinck (1770) schrijft over cassave :

De Cassave, Juca of Maniok wordt verdeeld in tweeërlei soorten....

Deze struik groeit ter hoogte van 7 of 8 Voeten: de Zoete brengt zyne Vruchten in acht Maanden voort, doch de bittere komt niet tot volwassenheid of rypheid dan na verloop van twaalf Maanden.

Ryp zynde, trekt men de gantsche Plant uit den Grond, en de Wortelen, die er af breeken, graaft men op....

Om de Cassave te verplanten, slaat men met een Houweel vyf of zes slagen in den Grond, om een hoop Aarde te maaken, waarin men vyf Stekken van de Steng steekt, ieder ter lengte van twaalf, veertien of zestien Duimen, vier in het Kruis en één in het midden zo diep, dat ieder Stek twee of drie leden boven den grond uitsteekt, aan ieder welker leden de Bladen uitspruiten: men maakt ieder hoop een of anderhalve Voet van malkander op een ry volgens een Lyn, op dat het Water daardoor kan afloopen. Dezelve worden tweemaal 's jaars van het Onkruid gezuiverd.

Ook Kappler schrijft in zijn „Surinam” (1887) over de zeer gunstige resultaten, welke met den verbouw van cassave in de kolonie verkregen worden.

Die Maniokwurzel ist sehr ergiebig, denn ein mittelmässig fruchtbarer Boden giebt auf einer Hectar 25.000 Kilo Wurzel [ong. 400 Picol.], aus denen man etwa 8500 Kilo Couac, oder die 
vegetabilische Nahrung von 32 Menschen während eines Jahres, erhält.

Auf fruchtbarem Boden kann man sogar mehr als das Doppelte erhalten.

Zum Urbarmachen des Landes aus Urwald sind auf einem Acker von der Grösse einer Hectare, für Pflanzen, Ernten und Fabrication, bei 8 stündiger Arbeit täglich, 734 Tage nötig, so dass zwei Leute imstande sind, in einem Jahre die Nahrung von 32, im gunstigen Falle sogar von 64 Menschen zu liefern.

Man pflanzt im Monat November, wenn die ersten Regen fallen, und schon nach 14 Tagen ist bei günstiger Witterung das Feld mit einem hellgelben Grün bedeckt. Gegen Juli ist die Wurzel reif. Die Indianen aber pflanzen und ernten das ganze Jahr.

Het Rapport aan het S. S. S. bevat eveneens veel goeds over de mogelijkheid van een cassavecultuur in Suriname.

In 1908 is het Dep. van Landbouw aangevangen met een onderzoek in te stellen naar de waarde van een deel der in het land voorkomende soorten en van een paar geïmporteerde.

Er werd een proefveld op goeden zandgrond op het land „Kwatta” nabij Paramaribo aangelegd van 35 varieteiten, ong. $\frac{1}{3}$ akker van ieder. Geplant was 3' $\times 3$ ' met één stek per plantplek. In 1909 werd geoogst van elke soort $\frac{1}{3}$ na 9, de rest na 12 maanden. De opbrengsten der veldjes van ong. $\frac{1}{3}$ akker zijn omgerekend per akker ( 0.43 H.A.).

Op 12 maanden leeftijd was de productie aanzienlijk hooger. De beide beste bleken te zijn:

de „alonsoe” met na 12 mnd. 15670 K.G. wortels per akker,

de „redi bita” of „boeroetikie” met na 12 mnd. 14350 K.G. wortels per akker.

Van de geïmporteerde bleek alleen de „white top" van Antigua met 10.800 K.G. per akker van eenig belang, hoewel ten achter staand bij meerdere reeds in het land gekweekte, behalve de bovengenoemde.

Een proefveld redi bita op Lelydorp op minder goed, rood zand, gaf in $190813.600 \mathrm{~K}$.G. wortels per akker.

Een volgende grooter proef in 1909/10 op „Kwatta” leverde na 12 mnd. op:

$$
\begin{array}{ll}
\text { voor de alonsoe } & 16500 \text { K.G. per akker } \\
\text { voor de redi bita } & 14400 \text { K.G. per akker. }
\end{array}
$$

In 1912 werd een proef op hetzelfde land genomen met 1- en 2- 
stek beplanting. Geoogst werd reeds na 9 maanden. De opbrengst was:

alonsoe, 1 stek beplanting 12300 K.G. per akker

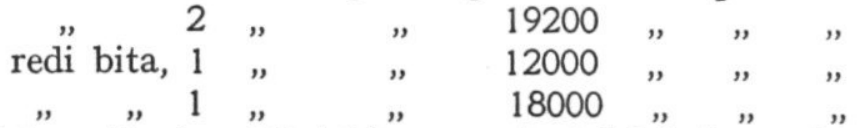

Het resultaat met 2 stekken per plantplek is dus veel gunstiger. Voor een leeftijd van 9 maanden is het resultaat buitengewoon gunstig......

....Vergelijkt men de in Suriname op goeden, maar niet superieuren grond verkregen producties van de alonsoe en de redi bita met de op Java bereikte, dan maken ze een uitstekend figuur.

Op Java worden dergelijke opbrengsten slechts op de rijkste gronden verkregen.

Volgens chemische analyse van het Proefstation bevatten beide varieteiten pl. m. $33 \%$ zetmeel, berekend van de geschilde wortels, wat ongeveer kan uitkomen op $28 \%$ van de ongeschilde.

Berekend per bouw voor de vergelijking met Java bedraagt de theoretische opbrengst der verschillende op „Kwatta” genomen proeven:

\begin{tabular}{|c|c|c|c|c|c|}
\hline & & $\begin{array}{c}\text { stek- } \\
\text { beplanting }\end{array}$ & leeftijd & picols & $\begin{array}{l}\text { picols zetmeel } \\
\text { per bouw }\end{array}$ \\
\hline alonsoe & • & 1 & 9 mnd. & 329 à $28 \%$ & 92 \\
\hline$"$ & $\cdot$ & 2 & 9 , & $513,28 \%$ & 143 \\
\hline " & . . & 1 & $12 "$ & $419,28 \%$ & 117 \\
\hline & . & 1 & 12 & $441,28 \%$ & 123 \\
\hline redi bita & & 1 & & $321,28 \%$ & 90 \\
\hline$" \quad$, & & 2 & 9 & $481,28 \%$ & 134 \\
\hline " & & 1 & 12 & $384,28 \%$ & 107 \\
\hline ", & 1 & 1 & 12 & $385,28 \%$ & 108 \\
\hline
\end{tabular}

Op een leeftijd van 9 maanden werd met 2 stek beplanting aanzienlijk meer product gemaakt dan op 12 maanden leeftijd met 1 stek. Het is jammer, dat niet werd nagegaan het resultaat na 12 maanden met 2 stekken per plantplek, waarmee nog grooter oogsten verwacht mogen worden.

Op Java is het planten met 1 stek regel.

Wie de praktijk van het tapiocabedrijf met eigen aanplant op 
Java kent, zal uit bovenstaande cijfers moeten concludeeren, dat ze zeer gunstig zijn, ook al moeten ze met het oog op den omvang der proeven en het langs chemischen weg berekende rendement als theoretisch beschouwd worden.

Met een productie van gemiddeld 75 pic. handelsmeel (vochtgehalte pl. m. $15 \%$ ) per bouw van 16 maands goed gecultiveerden aanplant op goede gronden is men op Java zeer tevreden..... ....dat zelfs bij een zeer lage markt van pl. m. $f 6 .-$ per pic. meel nog een ruime winstmarge voor het groot (tapioca) bedrijf op Java blijft, daar de kostprijs met rente en commissie zeg $f$ 4.- per pic. dooreen is, althans in normale omstandigheden was....

Om terug te keeren tot Suriname, moet speciaal gewezen worden op het groote voordeel van vroeger rijpen dan in Java's groote cassavecentra het geval is In Suriname is het gewas reeds volrijp met I2 maanden; op Java waar de cultuur op de hooger gelegen lichte vulkanische gronden gedreven wordt, bereikt men de hoogste productie's en rendementen na pl. m. I6 maanden.

Met zekerheid kan worden aangenomen dat èn klimaat èn een groot deel van den bodem van Suriname gunstiger eigenschappen voor een cassavecultuur bezitten dan die op Java, een land waar zeer mooie resultaten met deze cultuur worden verkregen.

(De Cassave is van Suriname naar Java overgebracht).

De opbrengsten in Suriname zijn per vlakte-eenheid en over een zelfden tijdsduur hooger dan op den besten Javagrond, de grond is in Suriname goedkooper, het transport van het bereide product naar de zeeschepen komt op Java op ruim 60 cent per picol - de cultuur aldaar wordt ver van de havens gedreven - waar dit in Suriname zich bepaalt tot enkele centen.

Een ruime beschikking over goedkoope werkkrachten en ploegvee is hetgeen Java op Suriname voorheeft.

Het gaat er om te weten of de eerste factor grootendeels, de tweede geheel bij een eventueele Surinaamsche cassavecultuur is uit te schakelen en door mechanische kracht te vervangen.

$\mathrm{Bij}$ het plantverband dat op Java het beste is gebleken, is, zoodra de cassaveaanplant eenige maanden oud is, handenarbeid voor het onderhoud urgent. 
Het Studie-Rapport zegt daarvan het volgende:

In de eerste maanden gebeurt het onderhoud middels ploegen tusschen de rijen met den lichten Javaanschen ploeg, tot 6 à 7 maal toe, met welke bewerking tevens wordt aangeaard. Om de planten wordt het onkruid uitgetrokken. Als men niet meer met den ploeg tusschen de rijen kan, wordt de grond schoon gehouden met den schoffel, waarbij er acht op moet worden geslagen, dat de wortelknollen, die dicht onder de oppervlakte liggen, niet geraakt worden. Later wordt alleen gewied en de beide laatste maanden wordt niets meer aan den aanplant gedaan; het gevaar van beschadiging der vol ontwikkelde wortels wordt dan te groot.

Met den korteren groeitijd in Suriname vermindert het aantal bewerkingen belangrijk.

Het schoonhouden van den grond met een schoffel geschiedt door arbeiders. De bladkronen sluiten zich aan en met een door vee getrokken werktuig is dit schoonhouden niet uit te voeren daar de bladeren hierdoor te veel zouden lijden, hetgeen van nadeeligen invloed zoude zijn op de productie.

Vergroot men nu de onderlinge afstanden der plantrijen dan zal het onderhoud langer zonder handenarbeid mogelijk zijn, om ten slotte bij een nog grooteren afstand geheel uitgeschakeld te kunnen worden.

De kans bestaat natuurlijk dat daardoor de productie zal verminderen, hoewel dit voor vruchtbaren grond niet vaststaat; dit is in de suikerrietcultuur voldoende bewezen.

Bij het oprichten van een proef-cultuurtuin is dit een der eerste zaken welke moet worden nagegaan; proeven kunnen dit slechts uitmaken; met praten erover komt men niet verder.

Wat nu de dierlijke trekkracht betreft kan met zekerheid worden aangenomen dat deze door mechanische kracht kan worden vervangen, vooral ook daar de cassavecultuur uitsluitend gedreven wordt op lichten, gemakkelijk te bewerken grond.

Met het oog op het mechanisch planten van cassavestekken is van belang hetgeen we daaromtrent in de Encyclopaedie van West-Indië lezen: Op zandgrond is het 
gewoonte ze vlak op den grond te leggen op $10 \mathrm{cM}$. diepte; twee stekken in één plantgat; de plantwijdte is 3 à 4 vt. in het vierkant.

Verder dient naar die oogstmethodes te worden gezocht, welke den minsten handenarbeid vereischen voor een snelle wijze van oogsten.

Verwerking van het ruwproduct.

Een onzer grootste deskundigen op het gebied van cassavecultuur, iemand met langjarige Javapraktijk, deelde mij mede dat een up-to-date cassave (tapioca) fabriek een zelfde kapitaal eischte als een goed ingerichte suikerfabriek.

Een cassavebedrijf bindt daardoor direct een groot kapitaal, wat een schaduwzijde is voor een land als Suriname waar ondernemers toch reeds liever niets wagen.

Mijn vraag of er een goede markt bestond voor in schijven gesneden en daarna gedroogde cassave moest hij ontkennend beantwoorden, evenals de mogelijkheid van het met voordeel verwerken van een dergelijk product in een bestaande daarvoor omgebouwde fabriek in Europa.

Ik voor mij ben nog niet zoo zeker dat een dergelijke methode niet met voordeel is toe te passen; de vrachttarieven zullen hier natuurlijk eveneens van invloed op zijn.

Intusschen viel mij een berichtje op in een der Surinaamsche bladen, 't welk een artikeltje uit de Daily Argosy (Britsch Guiana) van 28 Oct. '20, had overgenomen.

Den inhoud laat ik geheel voor rekening van den schrijver.

Het is ongetwijfeld belangrijk voor ons om te vernemen dat er in Britsch-Guiana een nieuwe industrie in opkomst is, namenlijk het cultiveeren van cassave op groote schaal.

De operaties worden geleid door Majoor A. V. Board, die de beheerder is van de Emido Comp. Sta. te Liverpool, een van de groepen, welke cassave voor verschillende doeleinden in Engeland verwerkt.

Deze firma was een der pioniers van de cassave-industrie en zij zijn de grootste importeurs van dit artikel waarvan het geïmporteerde kwantum verscheidene honderd duizenden ponden sterling per jaar waard is. 
Mr. Board verklaart dat zijn firma groote fabrieken in Engeland heeft alwaar de cassaven verwerkt worden en omgezet in prima kwaliteit producten en dat een van deze producten zeep zal zijn, nu door een Britsch chemist ontdekt is dat cassave voor de vervaardiging van dit artikel kan gebruikt worden. Men beweert dat cassavezeep een aangename zachtheid verleent aan de huid en ten zeerste wordt aanbevolen in medische kringen.

Mr. Board tracht zeer groote uitgestrektheden land in BritschGuiana te verkrijgen, welke hij zich voorstelt om met cassave in cultuur te brengen. Hij wil aanvangen met het beplanten van een paar honderd akkers op een daarvoor geschikte plaats gelegen, welk land als een ,nursery” (proefveld) zal dienen tot het verkrijgen van voldoende plantmateriaal dat thans in de kolonie ont breekt.

Over een jaar wordt dan in het groot aangevangen. Het zal tevens noodig zijn om geoefende werklieden in te voeren, omdat dit een der hoofdvoorwaarden van het succes van de onderneming is.

Majoor Board heeft een grondige kennis van de cultuur en een jaar voor dat de oorlog uitbrak, richtte hij een fabriek in Trinidad op met het doel de planters te toonen hoe of de mechanische droging van het product plaats vindt.

Ik heb tot heden gewezen op de beteekenis van de vorderingen der techniek voor de cultuur van rijst, suikerriet en cassave in praktisch niet bevolkte, overigens voor die cultuur gunstige factoren bezittende streken.

Ik wil er hier verder op wijzen dat het mogelijk is met uitsluiting van een groot percentage levende kracht cultures van andere belangrijke voedingsgewassen voor mensch en / of dier - , welke na of binnen een jaar vrucht geven, te drijven, als: mais, pinda, sojaboonen, tajer, yams, napi, switi patata enz.

Door toepassing van technische middelen zal de hoeveelheid te winnen zetmeel, vet, eiwit en suiker per vlakteeenheid per arbeider belangrijk vermeerderd kunnen worden, vooral als verder gebruik gemaakt wordt van andere vorderingen der wetenschap - bemesting selectie enz. -

$\mathrm{Bij}$ het voortschrijden der wetenschap zal deze hoeveelheid regelmatig stijgen.

De oude Herlein en later ook Kappler wezen op de 
mogelijkheid om door de arbeidskracht van een paar menschen voedsel voor een groot aantal te produceeren.

Dat zij beiden onafhankelijk van elkaar deze vergelijking maakten bewijst $\mathrm{m}$. i. dat zij in hun land voedselschaarschte voor een deel der bevolking hadden gekend.

Leest men de bladen in onzen tijd dan wordt men herhaaldelijk getroffen door op vergaderingen enz, uitgesproken meeningen: de jaarlijks geproduceerde hoeveelheid voedsel is voor de menschheid niet voldoende, vermeerdering der bevolking mag niet in dit tempo doorgaan.

M. i. is dit niet juist; er zijn in de wereld nog enorme uitgestrektheden voor cultures gunstig terrein, welke tot heden niet werden benut voor het vermeerderen der wereldvoedselproductie.

Tot voor weinige jaren hadden dergelijke terreinen betrekkelijk weinig waarde, omdat men er niet beschikte over voldoende werkkrachten en de aangevoerde den kostprijs der producten te veel drukten.

$\mathrm{Nu}$ we zoover zijn dat een groot deel der tot heden noodige werkkrachten kan worden uitgeschakeld, gaan we deze streken met andere oogen zien en nadert de tijd dat voor westersche landen een dergelijk tropisch bezit waarde begint te krijgen.

Waarde niet alleen voor het particulier initiatief, maar eveneens voor den Staat.

Beschikking over goedkoop hoofdvoedsel in groote hoeveelheden kan op den duur een machtig wapen zijn ter bestrijding der vele uitwassen der westersche staten.

Ik ben geen voorstander van staatsexploitatie tot het uiterste en zie geen toekomst in zuiver staatscultuur-ondernemingen, maar evenals het mogelijk is voor mineraalen olie-exploitatie gemengde maatschappijen op te richten zal hetzelfde voor cultuurondernemingen ook het geval kunnen zijn; particuliere ondernemingen dus gesteund met staatsgeld en voor een deel onder staatscontrôle.

In „Suriname's herleving op nieuwe basis," heb ik gewezen op de urgentie van het oprichten van een Departement van Opbouw dat o. m. verzamelt alles wat voor den wederopbouw van de kolonie van belang kan zijn. 
Dat Departement zal na eenigen tijd over belangrijke gegevens beschikken, welke verstrekt aan onze koloniale ondernemers deze tot daden moeten opwekken; ten einde des te sneller daden uit te lokken, kan het zich finantieel interesseeren van den Staat in cultuurondernemingen van waarde zijn.

Dit artikel was reeds eenige maanden oud toen mij de Novemberaflevering van het Archief der Java Suikerindustrie (1920) in handen kwam, waarin een ook voor Suriname belangrijk Rapport voorkomt van een EnquêteCommissie voor de machinale-grondbewerking op Java.

Ik zal er hier het een en ander uit aanhalen.

Gebrek aan werkvolk in de Java suikerindustrie is algemeen en toenemend, de werkwilligheid neemt af, er is dus een stijgend gebrek aan werkkrachten, zegt het Rapport.

van de 85 fabrieken, die steeds voldoende werkvolk hadden, klagen er 36 speciaal over 1919.

Afplanten geschiedt in toenemende mate te laat, bovendien blijkt uit de antwoorden dat bij het meerendeel der fabrieken gedeeltelijk op onvoldoend uitgezuurden grond geplant wordt.

Daarom is toepassing van machinale grondbewerking urgent geworden.

Deze kostte echter meer dan handenarbeid. Bedoelde méér kosten komen door verhoogde loonen den prijs van handenarbeid steeds meer nabij.

Wij weten, nog geenszins, waar wij met onze loonen voor veldarbeid aan toe zijn; zij vertoonen een stijgende lijn en zullen in de naaste toekomst nog meer omhoog gaan, zegt het Rapport.

Vet gedrukt lezen wij verder:

De enquête heeft dus onweerlegbaar uitgewezen dat machinale grondbewerking voor Java urgent is.

Java is echter gebonden aan een intensieve cultuur, welke aan de diverse machines veel hoogere eischen stelt dan een extensieve cultuur, waarvoor Suriname zulke gunstige voorwaarden biedt. 
Voor lichte en middelbare gronden, zegt het Rapport verder, blijken bruikbare ploegen en tractors aanwezig.

Voor zware gronden, welke vooralsnog beslist gegeuld moeten worden is, voor zoover wij weten, slechts een kabel-installatie op Java met eenig succes in gebruik.

Resumeerende besluit de commissie dat de toepassing nog zeer eenzijdig is en zich bepaalt tot het ploegen en daarnaast geulentrekken.

Voor graafwerk (Reynoso) is men nog niet geslaagd.

De machinale grondbewerking, eindigt het Rapport, is voor de Java-suikerindustrie urgent.... De vooruitzichten zijn een meer en meer gevoelde behoefte om sneller en intensiever te werken.

Voorgesteld wordt: Oprichting van een Instituut voor studie der machinale grondbewerking.

Het vraagstuk blijkt hoe langer zoo meer van algemeen belang en de financieele offers, die het vraagt, zijn te groot dan dat enkelen of een concern die kunnen dragen.

Het bevestigt hetgeen ik schreef in mijn laatste „suiker"'artikel.

Java staat voor groote moeilijkheden, welke men grootendeels tracht op te lossen door gebruikmaking van mechanische middelen, welke echter beter voldoen voor een extensieve cultuur op lichte of middelbare gronden dan voor een intensieve cultuur op zwaren grond.

Voor landen als Suriname begint een nieuwe tijd aan te breken!

Den Haag, Februari 1921. 